\title{
A High Performance Interleaved Bridgeless PFC for Nano-grid Systems
}

\author{
Guoen Cao*, Jea-Woo Lim**, Hee-Jun Kim ${ }^{\dagger}$, Huan Wang* and Yibo Wang*
}

\begin{abstract}
A high performance interleaved bridgeless boost power factor correction (PFC) rectifier operating under the critical current conduction mode $(\mathrm{CrM})$ is proposed in this paper to improve the efficiency and system performance of various applications, such as nano-grid systems. By combining the interleaved technique with the bridgeless topology, the circuit contains two independent branches without rectifier diodes. The branches operate in interleaved mode for each respective half-line period. Moreover, when operating in $\mathrm{CrM}$, all the power switches take on soft-switching, thereby reducing switching losses and raising system efficiency. In addition, the input current flows through a minimum amount of power devices. By employing a commercial PFC controller, an effective control scheme is used for the proposed circuit. The operating principle of the proposed circuit is presented, and the design considerations are also demonstrated. Simulations and experiments have been carried out to evaluate theoretical analysis and feasibility of the proposed circuit.
\end{abstract}

Keywords: PFC, Bridgeless technique, Interleaved topology, Critical conduction mode, Peak current mode control

\section{Introduction}

With the rapid development of power electronics technology, direct current nano-grid (DCNG) - a DC network that is interconnected with the AC main grid - becomes a good solution for energy management and utilization. It has been reported that using the $400 \mathrm{~V}$ DC grid improves total energy efficiency by approximately $18 \%$ [1]. Power factor correction (PFC) interface can be used to improve the power quality of the $\mathrm{AC}$ main grid and integrate $\mathrm{DCNG}$ with the existing electrical power system $[2,3]$.

However, conventional active PFC regulators are generally comprised of a front- end bridge diode and a high frequency boost converter. In the conventional boost PFC circuit, current passes through two slow diodes and one switch during the on-state, while during the off-state through two slow diodes and one fast diode [5-7]. Since typical DCNG system has relatively high power capacity, the high conduction losses caused by the forward voltage drop of the bridge diode and the high switching losses of switches (MOSFET and fast- recovery diode) begin to dramatically degrade overall system efficiency [8-10]. In addition, the heat generated within the semiconductors and inductors can destroy power devices and decreases system reliability [11].

To maximize the conversion efficiency, a lot of research

$\dagger$ Corresponding Author: Dept. of Electronic Systems Engineering, Hanyang University, Korea. (hjkim@hanyang.ac.kr)

* Institute of Electrical Engineering, Chinese Academy of Sciences and Key Laboratory of Solar Thermal Energy and Photovoltaic System, Chinese Academy of Sciences, China. (\{caoguoen, whuan, wyb\}@mail.iee.ac.cn)

** Dept. of Electronic Systems Engineering, Hanyang University, Korea. (limjaewoo87@naver.com)

Received: November 2, 2016; Accepted: February 2, 2017 have been investigated on the attractive techniques on PFC topologies. Two of them are the bridgeless topology and the interleaved technique.

To reduce the conduction losses, the rectifier diode and the boost converter are combined to develop the bridgeless PFC [12-14]. When compared with conventional circuits, this circuit could decrease the conduction losses without input rectifier bridge by allowing the current to flow through a minimum number of switching devices. Dualboost bridgeless PFC, shown in Fig. 1, is one of the most well-developed bridgeless topologies. In this circuit, two boost circuits operate for two half-line periods, respectively. The working principle of this converter is symmetrical within the positive and negative half-line cycles of the input voltage [7]. In this way, the limitation on power capacity that is caused by the diode bridge is eliminated. In addition, when compared with a single inductor, two inductors can achieve higher thermal performance.

However, the dual-boost bridgeless PFC is still not suitable for high- power DCNG applications. Although there are two boost phases in dual-boost topology, the operation of the circuit is still under single-phase mode. When one phase is operating, another one is in idle state. Single-phase boost converters under high power conditions have significant disadvantages, such as high current ripple,

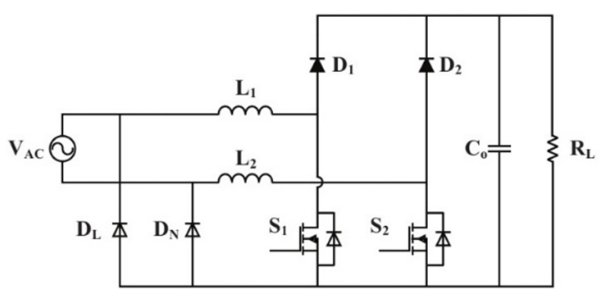

Fig. 1 Basic bridgeless boost PFC rectifier 


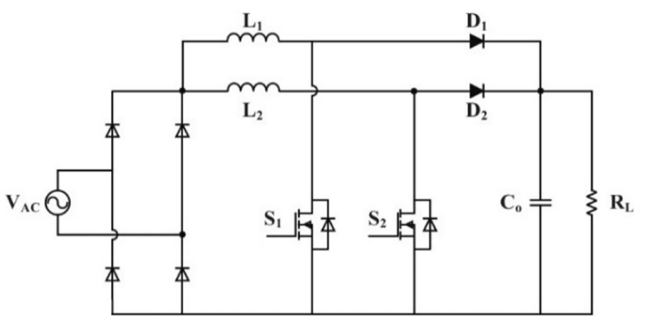

Fig. 2. Basic interleaved boost PFC circuit

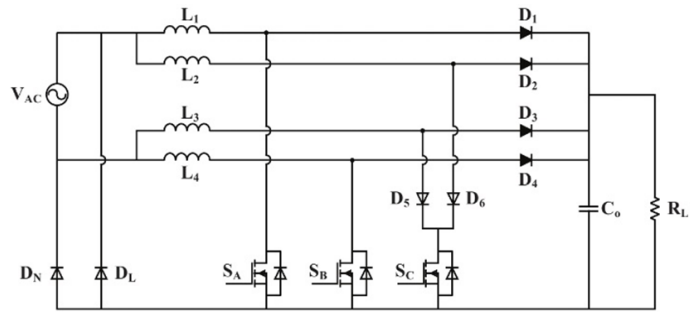

Fig. 3. The proposed PFC circuit high current stress for switches, large inductor size, hard switching operation, and reverse-recovery problems, leading to low efficiency and low energy density. Therefore, more phases should be added to increase the power capacity of the dual-boost PFC. However, direct paralleling more phases can lead low utilization problem of semiconductors.

Another effective technique is known as interleaved PFC, which usually combines more than two phases in parallel to be used in high power applications [15]. A conventional interleaved PFC topology is shown in Fig. 2. Owe to the interleaved operation, lower current ripple and smaller harmonic contents can be obtained for the input and output currents [16]. As a result, the size of the inductors and EMI filter can be decreased, as well as the switching losses.

However, this topology has the same drawbacks as the conventional boost PFC [3,17], such as the high conduction losses caused by the forward voltage drop of the rectifier diode and poor thermal performance, thereby decreasing system efficiency and reliability. To improve the performance of the interleaved PFC, the high conduction losses of the rectifier diode should be firstly considered.

In an attempt to develop a high-efficiency topology that is suitable for high power DCNG applications, this paper proposes a novel boost PFC rectifier that combines the bridgeless topology with the interleaved technique. The circuit contains two interleaved boost phases, two more inductors and one more power switch. Since the two interleaved branches are operated out of phase, lower conduction losses, lower current ripple, and smaller component size are achieved. When it is operated under critical current conduction mode (CrM), the rectifier is able to turn on the switches at zero current to reduce switching losses and to increase efficiency.

This paper mainly contains four sections. Section II describes the configuration and the operation principle of the proposed circuit. Section III proposed the key design considerations of the circuit. A comparison study with conventional topologies is also presented in this section. Section IV illustrates the simulation and experimental results. Finally, a conclusion is given in Section V.

\section{Configuration and Operation Principle}

\subsection{Circuit configuration}

The proposed circuit is shown in Fig. 3. The proposed circuit is composed mainly of two interleaved boost circuits, named as branch I and branch II. Each branch is composed of two phases converters that are parallel connected. Branch I consists of phase $I_{1}$ and phase $I_{2}$, where $\mathrm{I}_{1}$ is composed of $\mathrm{L}_{1}, \mathrm{~S}_{\mathrm{A}}$, and $\mathrm{D}_{1}, \mathrm{I}_{2}$ is composed of $\mathrm{L}_{2}, \mathrm{D}_{6}, \mathrm{~S}_{\mathrm{C}}$, and $\mathrm{D}_{2}$. Branch II consists of phase $\mathrm{II}_{1}$ and phase $\mathrm{II}_{2}$, where $\mathrm{II}_{1}$ is composed of $\mathrm{L}_{4}, \mathrm{~S}_{\mathrm{B}}$, and $\mathrm{D}_{4}, \mathrm{II}_{2}$ is composed of $\mathrm{L}_{3}, \mathrm{D}_{5}, \mathrm{~S}_{\mathrm{C}}$, and $\mathrm{D}_{4}$. $\mathrm{D}_{\mathrm{L}}$ and $\mathrm{D}_{\mathrm{N}}$ denote rectifier diodes, while $\mathrm{D}_{1} \sim \mathrm{D}_{4}$ are fast-recovery diodes. $\mathrm{L}_{1} \sim \mathrm{L}_{4}$ are boost inductors, and $\mathrm{C}_{\mathrm{O}}$ is output capacitor. $\mathrm{R}_{\mathrm{L}}$ denotes the equivalent resistive load.

In the proposed circuit, $\mathrm{S}_{\mathrm{C}}$ is the common switch shared by the interleaved branches. The current of each branch can be blocked by $D_{5}$ and $D_{6}$. Either $S_{A}$ or $S_{B}$ works in active state while another switch operates as a freewheeling diode during each half-line period of the line voltage, whereas $S_{C}$ is active for the whole-line period. Since the frequency of the line voltage is low $(60 \mathrm{~Hz}$ or $50 \mathrm{~Hz})$, slow-recovery diodes are feasible for $\mathrm{D}_{5}$ and $\mathrm{D}_{6}$.

To improve the common-mode EMI performance, branch I operates through $\mathrm{D}_{\mathrm{N}}$ during positive half-line cycle, while branch II operates through $\mathrm{D}_{\mathrm{L}}$ during negative half-line cycle. Although two additional inductors are employed when compared with conventional interleaved topologies, the proposed circuit can achieve good thermal performance. On the other hand, the two boost inductors of each branch can be coupled on one magnetic core, with considerable size and cost reduction resulting.

As can be seen from Fig. 3, the proposed circuit contains one more MOSFET than the dual-boost PFC. In addition, it requires two more slow diodes and two more fast diodes.

However, a much higher output power can be achieved by using the proposed circuit, while the dual-boost topology is not suitable for high-power applications.

\subsection{Circuit Operation Principle and Analysis}

The operation circuits of the proposed converter on the positive and negative half-line cycles are shown in Fig. 4(a) and Fig. 4(b), respectively.

In Fig. 4(a), on the positive half-line cycle, phase $\mathrm{I}_{1}\left(\mathrm{~L}_{1}{ }^{-}\right.$ $\left.\mathrm{S}_{\mathrm{A}}-\mathrm{D}_{1}\right)$ and phase $\mathrm{I}_{2}\left(\mathrm{~L}_{2}-\mathrm{D}_{6}-\mathrm{S}_{\mathrm{C}}-\mathrm{D}_{2}\right)$ are active alternatively.

When $\mathrm{S}_{\mathrm{A}}$ is turned on, the current flows through $\mathrm{L}_{1}$ $\mathrm{S}_{\mathrm{A}}-\mathrm{D}_{\mathrm{N}}$ path and the energy is stored in $\mathrm{L}_{1}$. When $\mathrm{S}_{\mathrm{A}}$ is turned off, the current flows through $\mathrm{L}_{1}-\mathrm{D}_{1}-\mathrm{D}_{\mathrm{N}}$ path, delivering the energy to the load. Likewise, phase $\mathrm{I}_{2}\left(\mathrm{~L}_{2}{ }^{-}\right.$ 
$\mathrm{D}_{6}-\mathrm{S}_{\mathrm{C}}-\mathrm{D}_{2}$ ) operates with the same principle in the interleaved mode. When $\mathrm{S}_{\mathrm{C}}$ is switched on, the current flows through $\mathrm{L}_{2}-\mathrm{S}_{\mathrm{C}}-\mathrm{D}_{6}$, and $\mathrm{D}_{\mathrm{N}}$. When $\mathrm{S}_{\mathrm{C}}$ is turned off, current flows through $\mathrm{L}_{2}, \mathrm{D}_{2}$, and $\mathrm{D}_{\mathrm{N}}$. During this half-line cycle the boost phases $\mathrm{II}_{1}\left(\mathrm{~L}_{4}-\mathrm{S}_{\mathrm{B}}-\mathrm{D}_{4}\right)$ and phase $\mathrm{II}_{2}\left(\mathrm{~L}_{3}-\right.$ $\mathrm{D}_{5}-\mathrm{S}_{\mathrm{C}}-\mathrm{D}_{4}$ ) are in an idle state.

The same results can be obtained during the negative half-line cycle. As shown in Fig. 4(b), when $S_{B}$ is switched on, energy is stored in $L_{4}$ through $\mathrm{S}_{B}-\mathrm{D}_{\mathrm{L}}$. When $\mathrm{S}_{\mathrm{B}}$ is switched off, energy is released through $\mathrm{L}_{4}-\mathrm{D}_{4}-\mathrm{D}_{\mathrm{L}}$. As the interleaved operation, phase $\mathrm{II}_{2}\left(\mathrm{~L}_{3}-\mathrm{D}_{5}-\mathrm{S}_{\mathrm{C}}-\mathrm{D}_{4}\right)$ operates in the same mode with out of phase.

According to the operation principle illustrated in Fig. 4, for branch $\mathrm{I}_{1}$ and branch $\mathrm{II}_{1}$, there is one slow diode, one fast diode, and one active power switch in the current flowing path for one phase, while one more slow diode, $\mathrm{D}_{5}$ for branch $\mathrm{I}_{2}$, and $\mathrm{D}_{6}$ for branch $\mathrm{II}_{2}$, are employed, resulting reduced amount of conduction devices comparing with traditional interleaved PFC circuit. As a result, the heat stresses as well as the conduction losses on the power semiconductors can be reduced, thus, the power convention efficiency can be improved.

It should be noted that $\mathrm{S}_{\mathrm{A}}$ and $\mathrm{S}_{\mathrm{B}}$ are driven through the same PWM signal, and $\mathrm{S}_{\mathrm{C}}$ is driven through the $180^{\circ}$ interleaved PWM signal. Therefore, the proposed circuit can operates the same with the conventional interleaved PFC. This control scheme simplifies the configuration of controller and can be implemented through employing standard commercial interleaved PFC controllers.

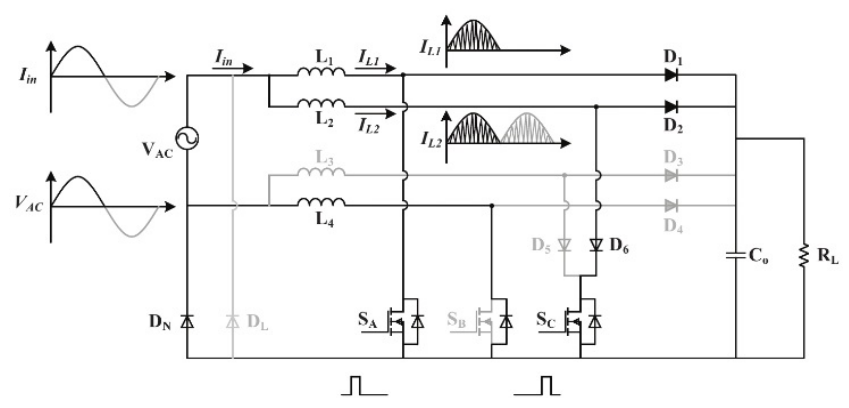

(a)

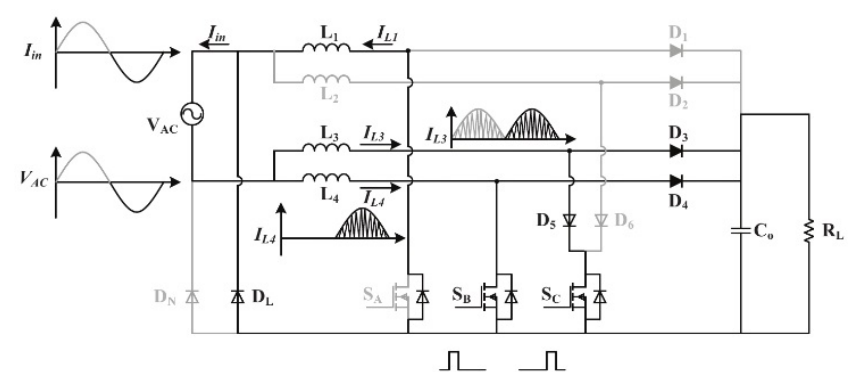

(b)

Fig. 4. Operating principle of the proposed PFC. (a) In positive half-line cycle and (b) in negative half-line cycle of the line voltage
Every interleaved phase of the proposed circuit can be operated under discontinuous current conduction mode or continuous current conduction mode. However, there are several advantages when operating under CrM. For example, the proposed circuit can be operated under zero current switching (ZCS) on the switch turn-on transition. The reverse-recovery issue of fast-recovery diodes can be significantly reduced. As a result, low current ripple and low switching losses can increase the circuit performance and reduce the EMI noise compared with conventional bridgeless PFC shown in Fig.1. The proposed circuit has another advantage of the reduced current stress for the semiconductor switches.

\section{Design Consideration and Comparison Study}

\subsection{Circuit design and comparison study}

To design a practical circuit, it is necessary to calculate the key parameters of the power components. During the analysis and evaluation, it is assumed that the unity power factor is achieved.

The input voltage can be described as

$$
v_{i n}(t)=\sqrt{2} V_{i n} \sin (\omega t)
$$

where $\mathrm{V}_{\text {in }}$ is the input RMS voltage. According to the voltage-second balance, we can get

$$
i_{L}(t)=\frac{v_{i n}(t) t_{o n}}{L}=\frac{\left(V_{o}-v_{i n}(t)\right) t_{o f f}}{L}
$$

where $t_{o n}$ and $t_{\text {off }}$ are the on and off periods of the main switch; and $\mathrm{V}_{\mathrm{O}}$ is the output voltage of the PFC circuit.

By operating in $\mathrm{CrM}$ and taking a constant switching ontime into consideration, the instantaneous switching frequency can be obtained as

$$
f_{s}(t)=\frac{V_{o}-v_{i n}(t)}{V_{o} t_{O N}} .
$$

The inductor current should reach zero at the end of the switching period, which can be determined according to the ripple current and input voltage conditions. As the minimum switching frequency should be selected under the low line input voltage, the inductor value is obtained as

$$
L=\frac{\eta\left[v_{i n}(t)\right]_{\text {min }}^{2}\left(V_{o}-\sqrt{2}\left[\left(v_{\text {in }}(t)\right)\right]_{\text {min }}\right.}{V_{o} P_{o}\left[f_{s}(t)\right]_{\min }}
$$

where $\left[v_{\text {in }}(t)\right]_{\min }$ is the minimum RMS value of the input voltage, $\left[f_{s}(t)\right]_{\text {min }}$ is the minimum switching frequency, $\mathrm{P}_{\mathrm{O}}$ is the rating output power, and $\mathrm{n}$ is the expected convention efficiency. 
As a result, the inductor peak current for one boost phase is expressed by

$$
I_{L p K}=\frac{\sqrt{2} P_{o u t}}{\eta\left[v_{\text {in }}(t)\right]_{\text {min }}}
$$

and the inductor RMS current of the boost inductor is

$$
I_{\text {Lrms }}=\sqrt{\frac{1}{2 \pi} \int_{0}^{2 \pi}\left(i_{L}(t)\right)^{2} d t}=\frac{P_{o u t}}{\sqrt{6}{ }_{\eta}\left[v_{\text {in }}(t)\right]_{\min }}
$$

Every boost circuit transports half of the output power for the whole circuit. As the result, the root mean square (RMS) current of the boost diode can be derived as

$$
I_{\text {Drms }}=\frac{I_{L p k}}{2 \sqrt{2}} \sqrt{\frac{4 \sqrt{2}\left[v_{i n}(t)\right]_{\min }}{9 \pi V_{o}}}
$$

Because of the CrM operation, reverse-recovery issues of the fast-recovery diodes can be reduced. As a result, only conduction losses should be considered.

As described in Section II, $\mathrm{S}_{\mathrm{A}}$ and $\mathrm{S}_{\mathrm{B}}$ work for the positive and negative line cycle, respectively, while $S_{C}$ is active for the whole line cycle. Therefore, the RMS currents flowing through $\mathrm{S}_{\mathrm{A}}$ and $\mathrm{S}_{\mathrm{B}}$ can be given by

$$
I_{r m s_{A B}}=\frac{I_{L p k}}{2 \sqrt{2}} \sqrt{\frac{1}{6}-\frac{4 \sqrt{2}\left[v_{i n}(t)\right]_{\min }}{9 \pi V_{o}}}
$$

while the RMS current of $\mathrm{S}_{\mathrm{C}}$ is obtained as

$$
I_{r m s_{C}}=\frac{I_{L p k}}{2} \sqrt{\frac{1}{6}-\frac{4 \sqrt{2}\left[v_{i n}(t)\right]_{\min }}{9 \pi V_{o}}}
$$

One of the most essential advantages of the dual-boost bridgeless PFC converter is the reduced conduction losses caused by the rectifier diode bridge. As shown in Fig. 1, the conduction losses of the slow diodes in dual-boost PFC can be calculated as

$$
P_{C_{-} \text {DualBoost }}=\frac{2 \sqrt{2} P_{o}}{\eta \pi\left[v_{\text {in }}(t)\right]_{\min }} V_{F}
$$

where $\mathrm{V}_{\mathrm{F}}$ is the forward voltage of the slow diodes. As there is one more slow diode during the switch on-state in each second boost phase, the conduction losses for the phases can be obtained as

$$
P_{C_{-} \text {Propesed }}=P_{C_{-} \text {DualBoost }} \sqrt{1+\varepsilon_{D}},
$$

where

$$
\varepsilon_{D}=\frac{\pi^{2}}{32}\left(\frac{1}{6}-\frac{1}{6}-\frac{4 \sqrt{2}\left[v_{i n}(t)\right]_{\min }}{9 \pi V_{o}}\right)
$$

Assuming the output voltage is $400 \mathrm{~V}$, in the universal input applications where the minimum input voltage is 85 $\mathrm{V}$, the maximum value of $\mathcal{E}_{D}$ is calculated as 0.038 from the above equation. As a result,

$$
\begin{aligned}
P_{C_{\text {Propesed }}} & =\sqrt{1+0.038} P_{C_{\text {DualBoost }}}, \\
& \approx 1.019 P_{C_{-} \text {DualBoost }}
\end{aligned}
$$

Therefore, although there is one more slow diode in the current path than the dual-boost bridgeless PFC circuit shown in Fig.1, the conduction losses of the proposed circuit is almost the same as those of the dual boost PFC circuit.

Based on the analysis above, a comparison among of the proposed circuit, conventional interleaved boost PFC, and dual-boost PFC under CrM operation is summarized in Table 1. It can be seen that the RMS inductor current of the proposed PFC is smaller than the others, which indicates that smaller inductor volume can be used in the circuit. In addition, current stresses of the boost diodes and the main switches of the proposed circuit are lower than those in the other circuits. Therefore, less-ideal and lower cost semiconductors can be used in the proposed circuit.

As the proposed circuit contains fewer power devices in the input current path than the conventional circuits, the conduction losses caused by slow diodes in the proposed

Table 1. Comparison of the conventional and the proposed circuits under CrM operation

\begin{tabular}{cccc}
\hline Item & Interleaved CrM PFC & CrM Dual-boost PFC & Proposed PFC \\
\hline Inductor RMS current & $\sqrt{6} I_{\text {Lrms }}$ & $\sqrt{2} I_{\text {Lrms }}$ & $I_{\text {Lrms }}$ \\
Inductor value & $L / 2$ & $L$ & $L$ \\
Boost diode RMS current & $\sqrt{2} I_{\text {Drms }}$ & $2 I_{\text {Drms }}$ & $I_{\text {Drms }}$ \\
Slow diode conduction loss & $2 P_{\text {C_DualBoost }}$ & $P_{\text {C_DualBoost }}$ & $P_{\text {C_DualBoost } \sqrt{1+\varepsilon_{\mathrm{D}}}}$ \\
MOSFET RMS current & $\sqrt{2} I_{\text {rms_AB }}$ & $4 I_{\text {rms_AB }}, S_{\mathrm{B}}: I_{\text {rms_AB }}$, \\
Power capacity & High & Medium & $S_{\mathrm{C}}: \sqrt{2} I_{\text {rms_AB }}$, \\
Current path & 2 slow diodes, & 1 slow diodes, & $S_{\mathrm{A}}, S_{\mathrm{B}}: 1$ slow diodes, 1 MOSFET \\
(switch on-state) & 1 MOSFET & 1 MOSFET & $S_{\mathrm{C}}: 2$ slow diodes, 1 MOSFET \\
Current path & 2 slow diodes, & 1 slow diodes, & 1 slow diodes, \\
(switch off-state) & 1 fast diode & 1 fast diode & 1 fast diode \\
\hline
\end{tabular}




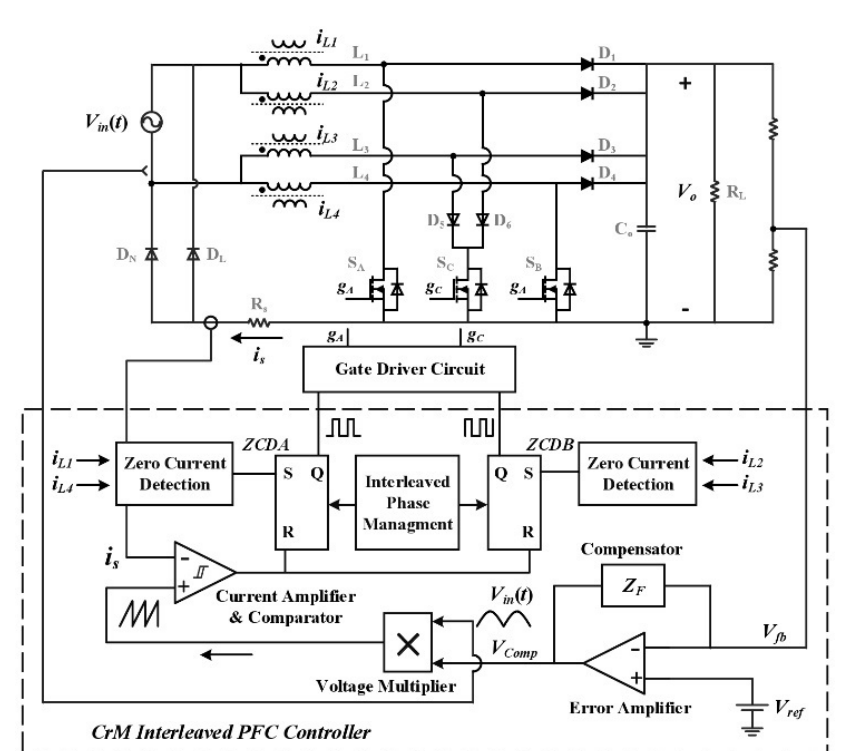

Fig. 5. Block diagram of the control scheme of the proposed circuit

circuit are much lower than those of the conventional circuits. In addition, the conduction losses in the proposed circuit are similar to those of the dual-boost bridgeless PFC.

As the proposed circuit is built through connecting two boost converters, with each working under interleaved technique, the proposed PFC remains the outstanding features of the bridgeless PFC circuits and the interleaved topologies. This performance can result in lower conduction losses and lower current ripple.

Although there seems more semiconductor devices in the proposed topology, higher efficiency, output power, and thermal management performance can be obtained when compared with the other two topologies under the same power capacity. In addition, because of the lower power stresses of the components, lower component cost can also be achieved with a proper design.

\subsection{Control scheme consideration}

Peak current mode control (PCMC) method is extensively employed in power converters and has many advantages, such as easy design and fast response. The simplified proposed circuit based on PCMC is shown in Fig. 5 .

Fig. 5. includes the signal feedback module, the PWM module, and the phase management module. As shown in Fig. 5, the current loop of the controller is inside of the voltage loop. The input current is controlled by the current loop to follow the input voltage waveform. The voltage loop controller regulates output voltage under CrM, while the switching frequency varies with constant on-time. The current loop and the voltage loop operate together by sampling the current is and output voltage $\mathrm{V}_{\mathrm{O}}$, respectively.

The zero current detection (ZCD) modules, shown as ZCDA and ZCDB, sample the zero current point of the

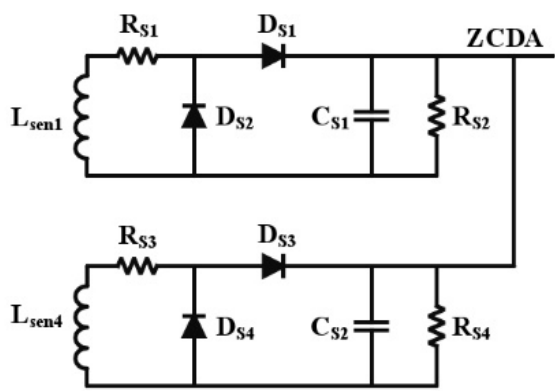

Fig. 6. Simplified zero current detection circuit of the proposed circuit

inductor currents $i_{L 1} \sim i_{L 4}$, which are employed as the off command to PWM signals. As a result, $\mathrm{S}_{\mathrm{A}}, \mathrm{S}_{\mathrm{B}}$, and $\mathrm{S}_{\mathrm{C}}$ are turned on once the valley of inductor currents are detected.

For branch I and branch II, the two phases operate independently. Since all the phases are operated under $\mathrm{CrM}$, the ZCD of the inductor currents becomes very important. An sample and effective ZCD circuit is designed to detect the valley of the inductor for the two phases of the branches. One of the ZCD circuits is shown in Fig. 6.

As shown in the circuit, two inductor current sensing circuits are connected in parallel. $\mathrm{L}_{\mathrm{sen} 1}$ senses the current of $\mathrm{L}_{1}$ during the positive half-line period as $\mathrm{i}_{\mathrm{Ls} 1}$. Meanwhile, $\mathrm{i}_{\mathrm{Ls} 4}$ is zero and taken to ZCDA through $\mathrm{D}_{\mathrm{S} 3}$. In the same way, during the negative half-line period, $i_{\text {Ls } 4}$ is segregated from ZCDA by $\mathrm{D}_{\mathrm{S} 3}$ while $\mathrm{i}_{\mathrm{Ls} 1}$ is taken through $\mathrm{D}_{\mathrm{S} 1}$. Therefore, we can get the voltage of ZCDA, $v_{\mathrm{ZCDA}}$, as

$$
v Z C D A=\left\{\begin{array}{l}
i_{L s 1} R_{S 2}, \text { During positive cycle } \\
i_{L s 4} R_{S 4}, \text { During negative cycle }
\end{array}\right.
$$

For the ZCDB circuit, the same results can be obtained. It should be noted that, although there are four channels in the proposed circuit and two ZCD channels in the PFC controller, the ZCD module can capture the valley of the inductor current effectively, making it easy to control the proposed circuit using commercial PFC controllers.

\section{Simulation and Experimental Results}

\subsection{Simulation results}

To evaluate the feasibility of the proposed circuit, a simulation circuit based on Pspice was developed. The model was designed according to the specifications shown in Table 2. A commercial PFC controller, UCC28063 from TI, was employed. Fig. 7 illustrates the main power stage of the simulation circuit.

Fig. 8 presents the switching waveforms of the branch I under steady-state. As can be seen, the $\mathrm{S}_{\mathrm{A}}$ and $\mathrm{S}_{\mathrm{C}}$ are turned on under ZCS conditions. Thus, the proposed circuit can achieve low switching losses and low reverse-recovery 
Table 2. Parameters of the simulation circuit

\begin{tabular}{ccc}
\hline Items & Symbols & Values \\
Input line frequency & $\mathrm{f}_{\mathrm{L}}$ & $60 \mathrm{~Hz}$ \\
Input line voltage & $\mathrm{V}_{\mathrm{ac}}$ & $85 \mathrm{~V}-265 \mathrm{~V}$ \\
Rated power & $\mathrm{P}_{\text {out }}$ & $600 \mathrm{~W}$ \\
Output voltage & $\mathrm{V}_{\mathrm{O}}$ & $385 \mathrm{VDC}$ \\
Inductor & $\mathrm{L}_{1} \sim \mathrm{L}_{4}$ & $80 \mathrm{uH}$ \\
Output capacitor & $\mathrm{C}_{\text {out }}$ & $500 \mathrm{uF}$ \\
\hline
\end{tabular}

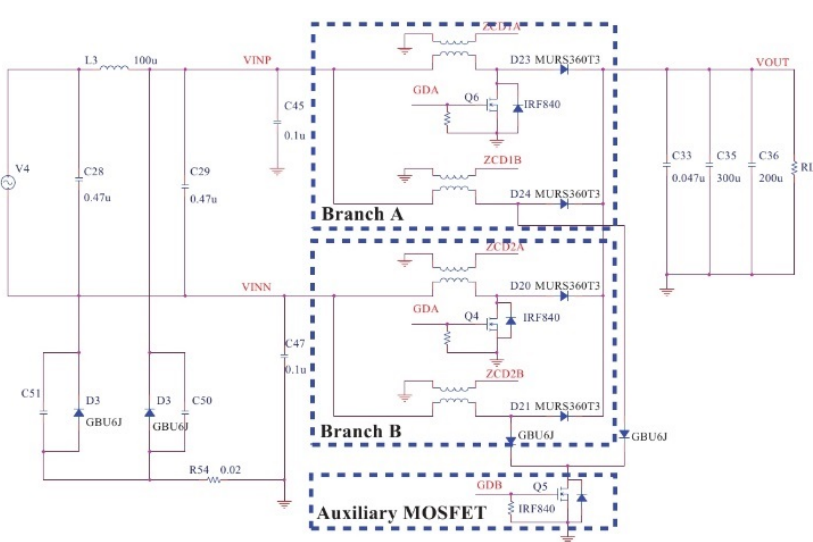

Fig. 7. Simulated power stage of the proposed circuit based on Pspice

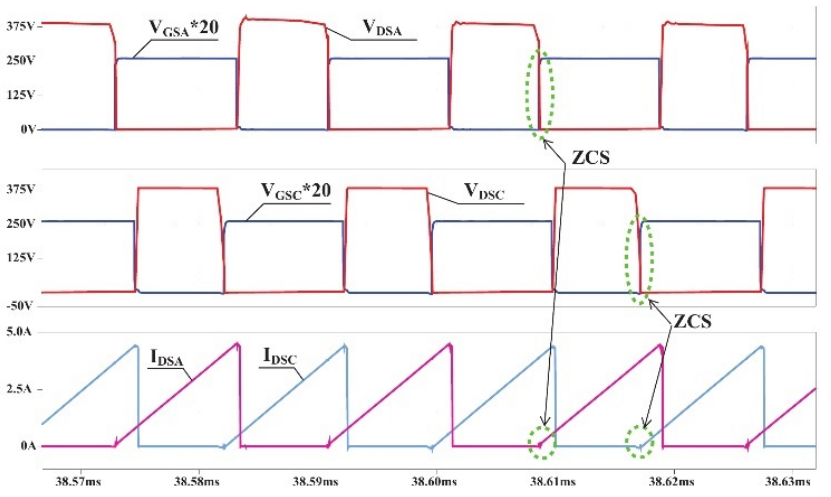

Fig. 8. Waveforms of drain-to-source voltage, driver signal, and seitching current of $S_{A}$ and $S_{C}$

losses.

The currents of $L_{l}$ and $L_{2}$ are shown in Fig. 9, as well as the driver signals of $S_{A}$ and $S_{C}$. It can be seen that the effective frequency of ripple current is increased twice. The peak value of the output current ripple is also reduced half compared to the inductor current.

Fig. 10 illustrates the current waveforms of $L_{l}$ and $L_{2}$ in branch $\mathrm{I}$ under $220 \mathrm{~V}_{\mathrm{AC}}$ line input and rated-load conditions. The switching waveforms of $\mathrm{S}_{\mathrm{A}}$ and $\mathrm{S}_{\mathrm{C}}$ are also presents in Fig. 10. As analyzed in the operation principle, $\mathrm{S}_{\mathrm{A}}$ operates in half-line period and $\mathrm{S}_{\mathrm{C}}$ is active during the whole line periods.

\subsection{Experimental results}

A $600 \mathrm{~W}$ experimental prototype circuit was built and

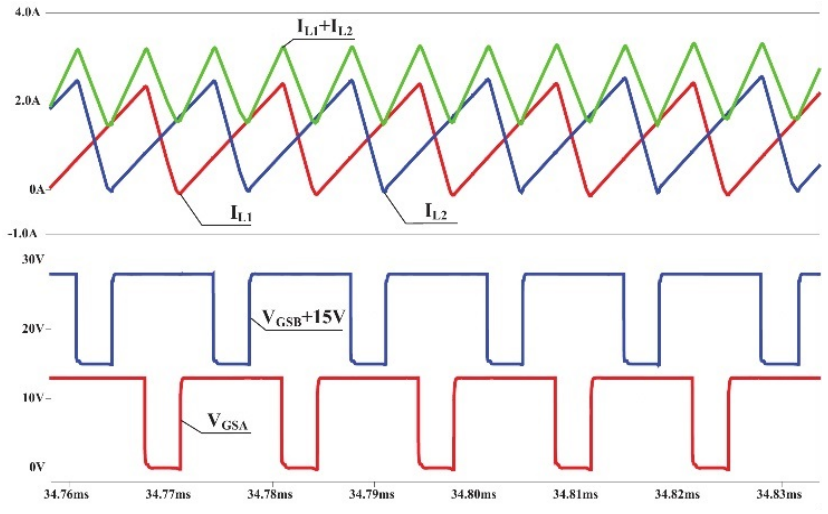

Fig. 9. Waveforms of the current waveforms of $L_{1}$ and $L_{2}$ as well as output current.

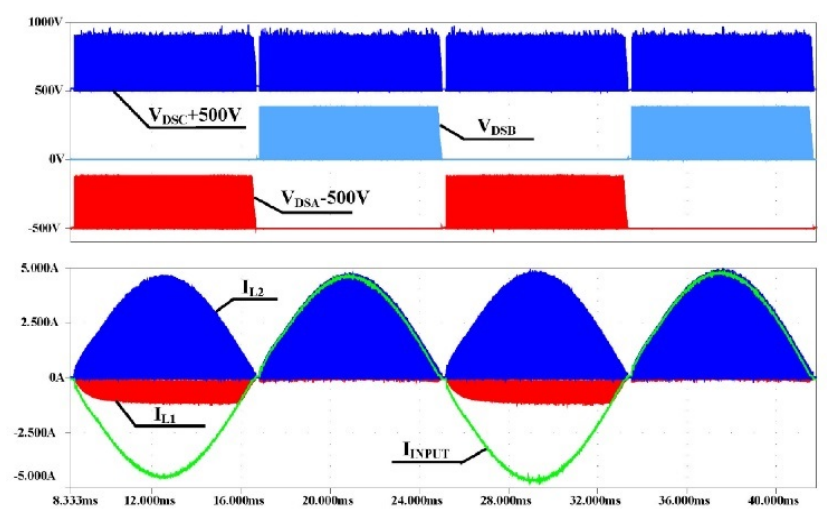

Fig. 10. Waveforms of inductor current waveforms of branch I, switching waveforms of $S_{A}$ and $S_{C}$, and the input current waveform

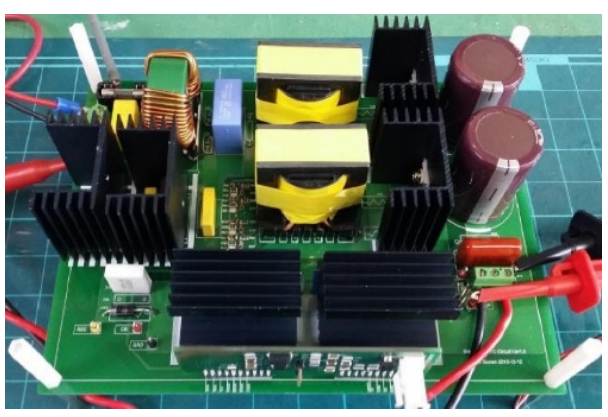

Fig. 11. Photograph of the prototype converter

tested for a laboratory DCNG system, as shown in Fig. 11. The specifications of the circuit are the same as the parameters of the simulated circuit shown in Table 2. In the future work, higher power prototype circuit will be designed to test detailed performance.

The switching voltages of the switches $S_{A}$ and $S_{B}, V_{d s} S A$ and $V_{d s} S B$, are shown in Fig. 12, respectively. The current of $L_{1}$ and $L_{4}$, noted as $I_{L 1}$ and $I_{L 2}$, and the input voltage, $V_{\text {input }}$, are presented in Fig. 13, respectively. As can be seen, $\mathrm{S}_{\mathrm{A}}$ and $\mathrm{S}_{\mathrm{B}}$ are active during each half-line period, which can decrease the heat density. The inductor currents follow 


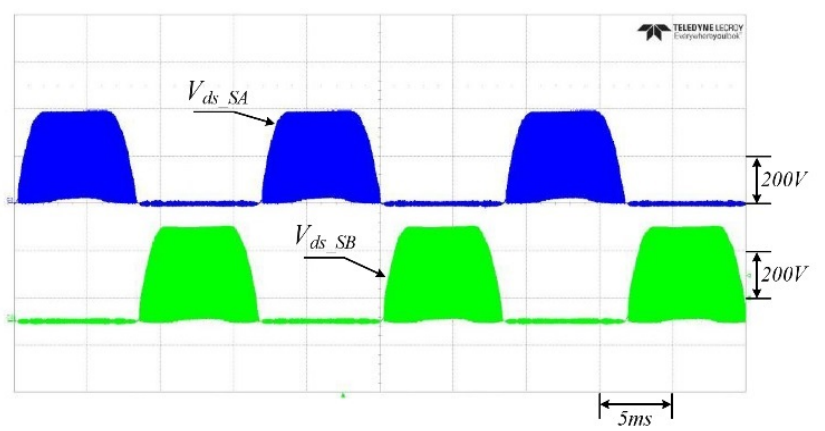

Fig. 12. Experiential switching voltages waveforms of $S_{A}$ and $S_{B}$

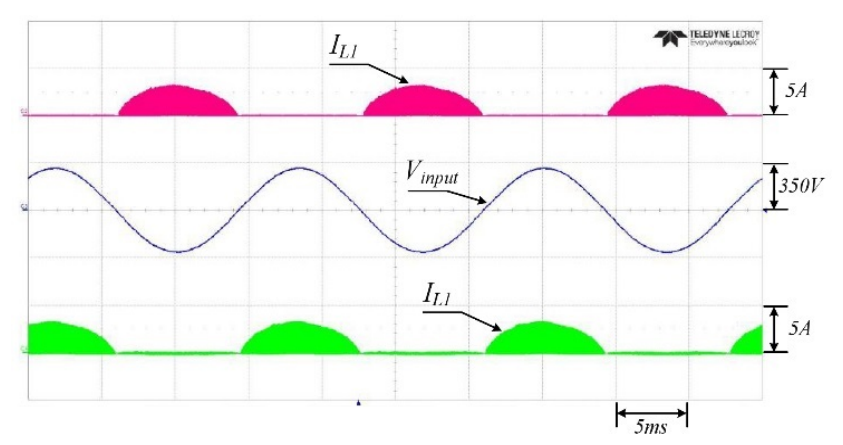

Fig. 13. Inductor current and the input voltage waveforms

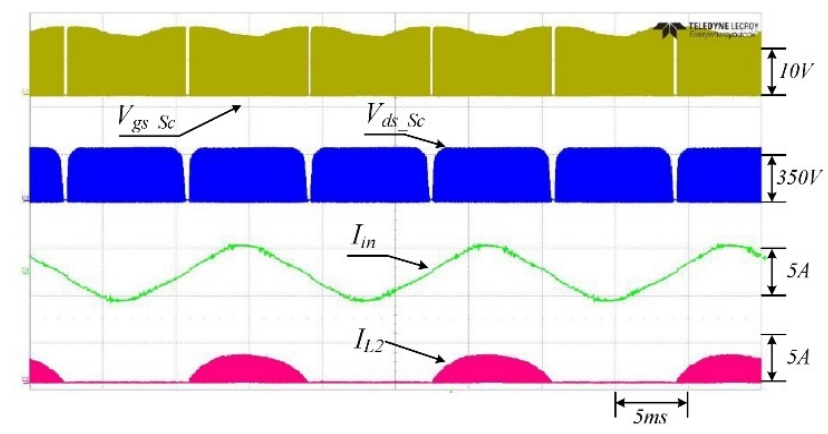

Fig. 14. Switching waveforms of $S_{C}, L_{2}$, and the input current $I_{\text {in }}$

the shape of input voltage in CrM operation. When $L_{1}$ operates in the positive half-line period, $L_{4}$ keeps idle with a zero inductor current. Similarly when $L_{4}$ is active in the negative half-line period, $L_{l}$ is in idle state.

The current waveform of $L_{2}$, the switching waveforms of $S_{C}$, and the input current $I_{\text {in }}$ are shown in Fig.14. $S_{C}$ operates during the whole-line cycle, while $L_{2}$ and $L_{3}$ are employed for each half-line cycle. Two switches, $\mathrm{S}_{\mathrm{A}}$ and $\mathrm{S}_{\mathrm{C}}$ or $\mathrm{S}_{\mathrm{B}}$ and $\mathrm{S}_{\mathrm{C}}$, are active under interleaved operation during each half-line period, resulting the same operation as the conventional interleaved circuit. However, it should be noted that the number of conduction devices is decreased by employing bridgeless topology.

The input current and voltage, the output voltage, and the sensing signal of output current under full load

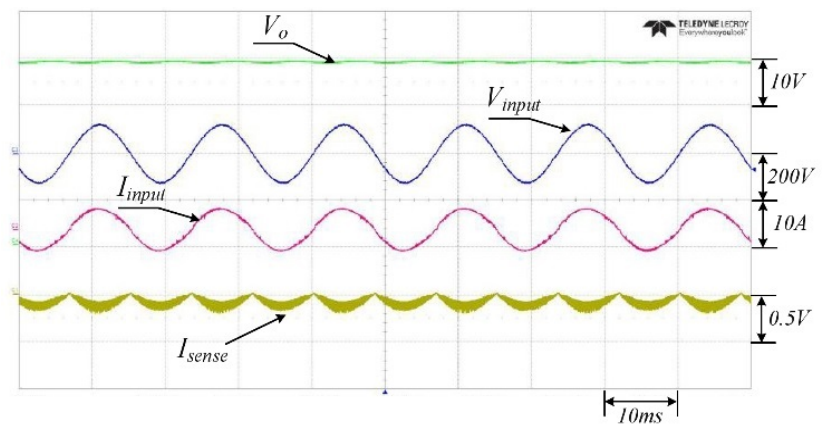

Fig. 15. Waveforms of the proposed PFC circuit under rated load and $220 \mathrm{~V}$ input voltage.

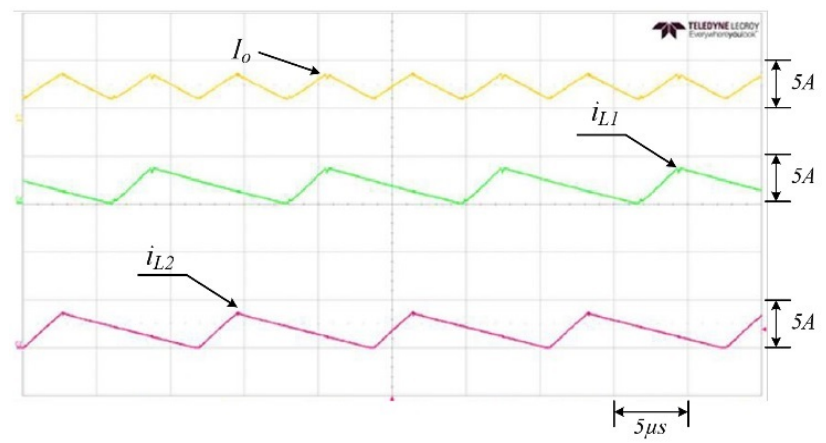

Fig. 16. Waveforms of the inductor currents and the total output current

condition are shown in Fig. 15. The input current and the input voltage are in the same phase and are practically sinusoidal. The output voltage is constant with a very low ripple.

The output current and the inductor current waveforms in branch I are shown in Fig. 16. CrM operation of the circuit is shown through the waveforms. As the same as the simulation results, the ripple frequency of total current is increased by twice and the peak value of current ripple was significantly decreased when compared with the inductor ripple current, which is a benefit of the interleaved operation. Therefore, the size of EMI filter can be reduced. In addition, reserve-recovery noise can also be decreased significantly.

The measured power factors (PF) results of the proposed circuit under low-line and high-line input voltages are shown in Fig. 17. It can be seen that the proposed circuit achieves very high PF under low line input voltage of $85 \mathrm{~V}$, which is above 0.98 from $10 \%$ light load to the rated load. Under the high line input voltage of $265 \mathrm{~V}$ and the rated load, the PF of the proposed circuit is higher than $99.6 \%$.

The measured total harmonic distortions (THD) results under rated load and input voltage of $265 \mathrm{~V}$ conditions are shown in Fig. 18. The results show that very low THD results are achieved for the proposed PFC circuit, which can meet the IEC61000-3-2 Class D requirements.

The measured system efficiencies of the proposed circuit and a conventional interleaved PFC under $85 \mathrm{~V}$ and $265 \mathrm{~V}$ 


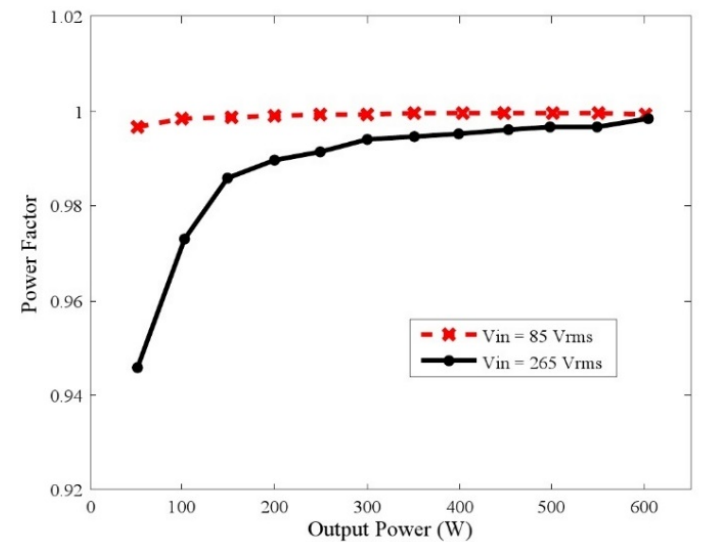

Fig. 17. System power factor of the proposed circuit under high line and low line voltages.

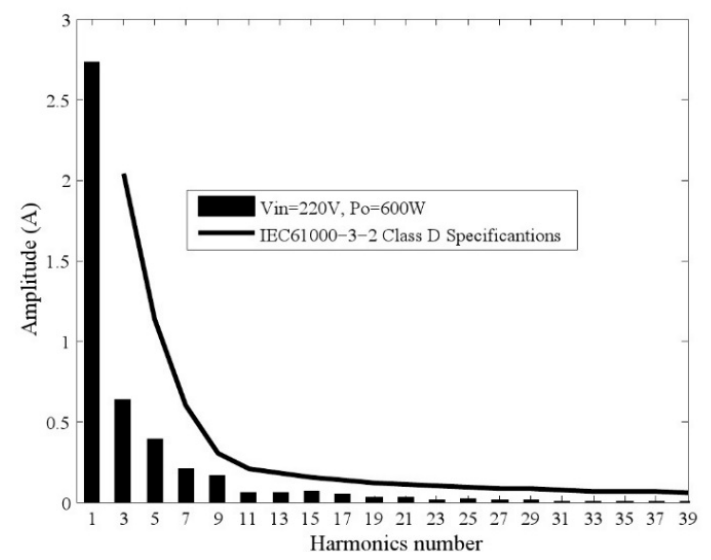

Fig. 18. Measured system THD under $265 \mathrm{~V}$ input and rated load

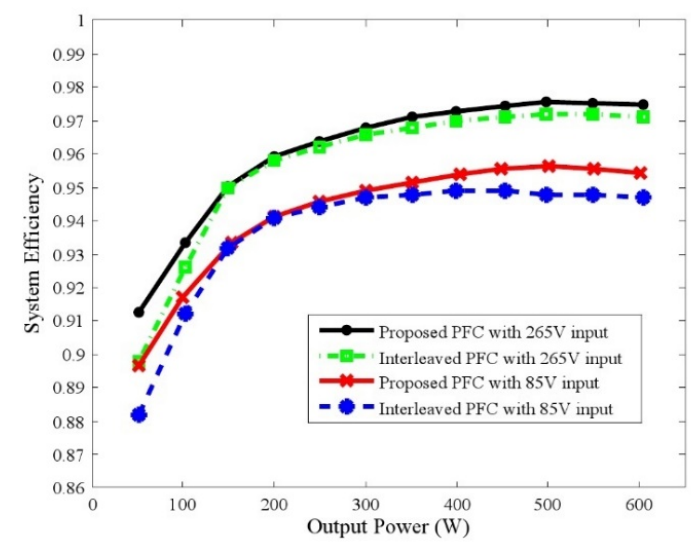

Fig. 19. Experimental results of system efficiency

input voltages are shown in Fig. 19. As the dual-boost PFC is in one-phase structure, which is not suitable for DCNG applications, it has been left off the comparison list. According to Fig. 19, the proposed circuit has higher efficiency than the conventional one within the whole load range. Under full load conditions of $85 \mathrm{~V}$ input, the improved efficiency can reach as high as $0.8 \%$, while the value is up to $0.35 \%$ at $265 \mathrm{~V}$ input. It can be seen that high efficiency improvement can be obtained under heavy load for the proposed circuit, because the device number in the current flowing path is decreased.

For the proposed circuit, the efficiency under rated load and input voltage of $85 \mathrm{~V}$ is up to $95.6 \%$. The maximum efficiency is obtained as $97.6 \%$, that is achieved at $500 \mathrm{~W}$ load at $265 \mathrm{~V}$ input. During the whole load range of $265 \mathrm{~V}$ input, the system efficiencies are always higher than $90 \%$. As the power capacity becomes higher, the benefit in terms of the efficiency of the proposed circuit becomes larger than the conventional circuits. Therefore, the proposed topology is more suitable for higher power applications, such as nano-grid systems, high power battery chargers, etc.

\section{Conclusion}

In this paper, a high performance interleaved bridgeless boost PFC circuit has been proposed for nano-grid applications. The circuit combines the conventional interleaved technique with bridgeless topology. The high conduction losses caused by the forward voltage of the rectifier diode bridge have been reduced significantly by the bridgeless technique. With operating as interleaved topology in CrM, this circuit is suitable for higher power applications with lower current ripple requirement. Simulated circuit based on Pspise was developed and a $600 \mathrm{~W}$ prototype circuit was designed to evaluate the feasibility of the proposed circuit. Very high PF and low THD were obtained through the experiments. In addition, the maximum system efficiency of $97.6 \%$ was obtained under 500 load and input voltage of $265 \mathrm{~V}$.

\section{References}

[1] P. Tenti, A. Costabeber and P. Mattavelli, "Improving power quality and distribution efficiency in microgrids by cooperative control of Switching Power Interfaces," Power Electronics Conference (IPEC), 2010 International, Sapporo, 2010, pp. 472-479.

[2] S. Basu and M. H. J. Bollen, "A novel common power factor correction scheme for homes and offices," in IEEE Transactions on Power Delivery, vol. 20, no. 3, pp. 2257-2263, July 2005.

[3] H. Ribeiro, B.Borges, "Techniques to obtain singlestage power supplies with power factor correction (pfc). “international Journal of Electronicsi vol. 98, no. 4, pp. 487-504, April, 2011.

[4] Chien-Ming Wang, "A novel zero-Voltage-switching PWM boost rectifier with high power factor and low conduction losses," in IEEE Transactions on Industrial Electronics, vol. 52, no. 2, pp. 427-435, April 2005.

[5] B. Prakash and S. Prakash, "Analysis of high DC bus 
voltage stress in the design of single stage single switch switch mode rectifier," Proceedings of the IEEE International Symposium on Industrial Electronics, 2005. ISIE 2005., Dubrovnik, Croatia, 2005, pp. 505511 vol. 2.

[6] L. Huber, Y. Jang and M. M. Jovanovic, "Performance Evaluation of Bridgeless PFC Boost Rectifiers," in IEEE Transactions on Power Electronics, vol. 23, no. 3, pp. 1381-1390, May 2008.

[7] Po-Wa Lee, Yim-Shu Lee, D. K. W. Cheng and XiuCheng Liu, "Steady-state analysis of an interleaved boost converter with coupled inductors," in IEEE Transactions on Industrial Electronics, vol. 47, no. 4, pp. 787-795, Aug 2000.

[8] C. Zheng, H. Ma, B. Gu, R. Chen, E. Faraci, W. Yu, J. S. Lai, and H. S. Koh, "An improved bridgeless sepic pfc rectifier with optimized magnetic utilization, minimized circulating losses, and reduced sensing noise," in Applied Power Electronics Conference and Exposition (APEC), 2013 Twenty-Eighth Annual IEEE, 2013, pp. 1906-1911.

[9] C. Petrea and M. Lucanu, "Bridgeless Power Factor Correction Converter Working at High Load Variations," 2007 International Symposium on Signals, Circuits and Systems, Iasi, 2007, pp. 1-4.

[10] E. Firmansyah, S. Tomioka, S. Abe, M. Shoyama and T. Ninomiya, "A critical-conduction-mode bridgeless interleaved boost power factor correction," INTELEC 2009 - 31st International Telecommunications Energy Conference, Incheon, 2009, pp. 1-5.

[11] G. Yao, A. Chen and X. He, "Soft Switching Circuit for Interleaved Boost Converters," in IEEE Transactions on Power Electronics, vol. 22, no. 1, pp. 8086, Jan. 2007.

[12] D. J. S. Newlin, R. Ramalakshmi and S. Rajasekaran, "A performance comparison of interleaved boost converter and conventional boost converter for renewable energy application," Green High Performance Computing (ICGHPC), 2013 IEEE International Conference on, Nagercoil, 2013, pp. 1-6.

[13] S. J. Bindu and C. A. Babu, "Analysis and design of a Single Stage Single Switch Power Factor converter to reduce bus voltage stress with high input power factor and fast output voltage regulation," Control and Modeling for Power Electronics (COMPEL), 2012 IEEE 13th Workshop on, Kyoto, 2012, pp. 1-7.

[14] R. Martinez and P. N. Enjeti, "A high-performance single-phase rectifier with input power factor correction," in IEEE Transactions on Power Electronics, vol. 11, no. 2, pp. 311-317, Mar 1996.

[15] B. Su, J. Zhang and Z. Lu, "Single inductor threelevel boost bridgeless PFC rectifier with nature voltage clamp," Power Electronics Conference (IPEC), 2010 International, Sapporo, 2010, pp. 2092-2097.

[16] G. Cao and H. J. Kim. "Improved bridgeless interleaved boost pfc rectifier with optimized magnetic utilization and reduced sensing noise." Journal of Power Electronics, vol. 14, no. 5, 815-826, Sep 2014.

[17] G. Cao and H. J. Kim, "An improved bridgeless interleaved boost PFC rectifier with optimized magnetic utilization and reduced sensing noise," Industrial Technology (ICIT), 2014 IEEE International Conference on, Busan, 2014, pp. 436-441.

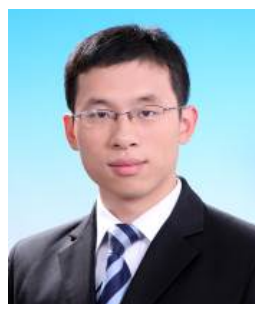

Guoen Cao received the B.S degree in electrical engineering from Shandong University of science and technology, Qingdao, China, in 2009, the M.S. degree in electrical engineering from Beihang University, Beijing, China in 2012, and the Ph.D. degree in Electronics System Engineering from Hanyang University, Seoul, Korea in 2015. He is currently an Assistant Professor of Institute of Electrical Engineering, Chinese Academy of Sciences. His current research interests include resonant and soft switching power converter design, high efficiency power supplies in renewable energy applications, wide bandgap semiconductors and application, and electric vehicles.

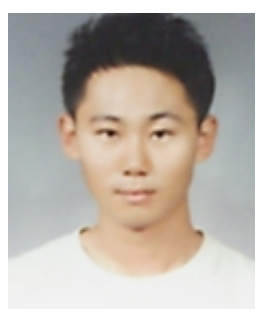

Jae-Woo Lim received the B.S. degree in Electronic and Communication technology from the Mokpo National Maritime University, Mokpo, Jeollanamdo, Korea, in 2012. He is currently pursuing the Integrated Master and Ph.D. degree in Electronics System Engineering with Hanyang University, Seoul, Korea. His current research interests include DC/DC converters for electric vehicle and DC/DC converter using wide bandgap semiconductors.

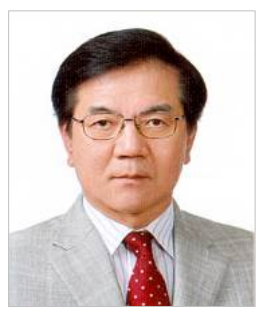

Hee-Jun Kim received the B.S and M.S. degree in Electronics Engineering from Hanyang University, Seoul, Korea, in 1976 and 1978, respectively, and the Ph.D. degree in Electronics Engineering from Kyushu University, Fukuoka, Japan, in 1986. Since 1987, he has been with the department of

Electronic Systems Engineering, Hanyang University, Ansan, Korea, where he is currently a professor. His current interests include switching power converters, electronic ballasts, soft switching techniques, and analog signal processing. Prof. Kim is the President of the Korean Institute of Electrical Engineers in 2015 and a senior member of IEEE. 


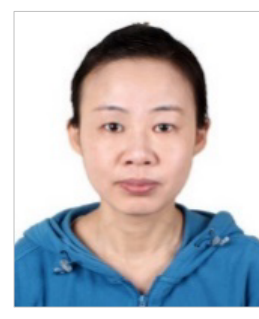

Huan Wang received the B.S. and M.S. degrees in Power Electronics from Beijing Jiaotong University, Beijing, China, in 2001 and 2004, respectively. In 2004, she joined Institute of Electrical Engineering, Chinese Academy of Sciences, where she became a senior engineer in 2013. Her current research interests include PV system and dc/dc converter applied in HVDC grid.

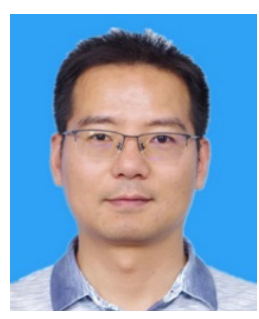

Yibo Wang received the B.S. and M.S. degrees in power electronics from Xinjiang University, Xinjiang, China, in 1994 and 2001, respectively, and the Ph.D. degree in Power Electronics from Chinese Academy of Sciences, Beijing, China, in 2009. He is currently a professor with Institute of Electrical Engineering, Chinese Academy of Sciences. His current research interests include PV system and microgrid system. 